\section{TAGUCHI ORTHOGONAL DESIGN FOR OPTIMIZING A UNIFIED TERNARY PROCESS TO VALORIZE OIL PALM LEAVES FOR NANOCELLULOSE ISOLATION}

Shamini Shunmugama,b, Hwee Li Teoa,b, Nursyafiqah Eliasa,b, Roswanira Abdul Wahaba,b*

aDepartment of Chemistry, Faculty of Science, Universiti Teknologi Malaysia, 81310 UTM Johor Bahru, Malaysia bEnzyme Technology and Green Synthesis Group, Faculty of Science, Universiti Teknologi Malaysia, 81310 UTM Johor Bahru, Malaysia
Article history

Received

7 August 2020

Received in revised form

18 January 2021

Accepted

25 January 2021

Published online

23 February 2021

*Corresponding author roswanira@kimia.fs.utm.my

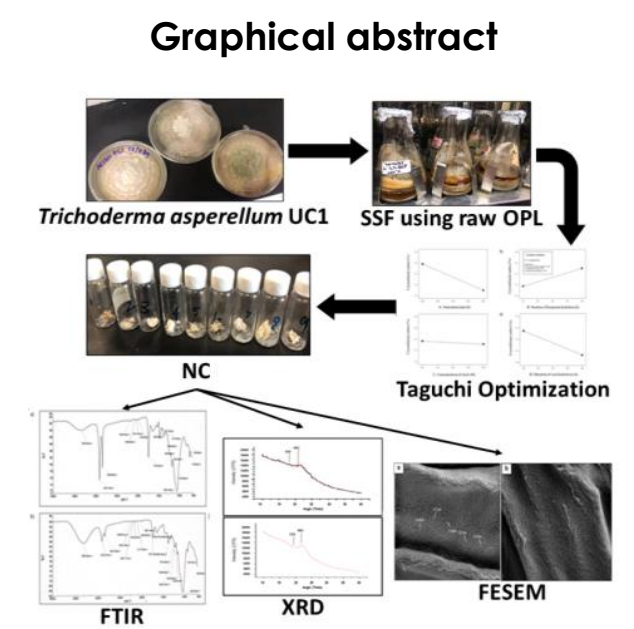

FTIR

\begin{abstract}
Oil palm leaves (OPL), as the major component of oil palm biomass, was capitalized for the isolation of nanocellulose (NC) by unified ternary acoustic, chemical- and enzyme-assisted techniques. This study aimed to statistically optimize the extraction parameters via the Taguchi Design for sonication time, duration of enzymatic hydrolysis, the concentration of acid, and the duration of acid hydrolysis, for the highest crystallinity of the isolated NC. The optimum condition required a sonication duration of $20 \mathrm{~min}, 1 \mathrm{~h}$ of acid hydrolysis in $6 \mathrm{M}$ of $\mathrm{H}_{2} \mathrm{SO}_{4}$ and $1 \mathrm{~h}$ of enzymatic hydrolysis that resulted in the production of $\mathrm{NC}$ with a maximum $68.2 \%$ crystallinity index, based on X-ray diffraction (XRD) data. Duration of sonication time and acid hydrolysis was crucial for improving the crystallinity of isolated $\mathrm{NC}$. The reduced $\mathrm{C}=\mathrm{O}$ and $\mathrm{C}=\mathrm{C}$ peaks at $1734 \mathrm{~cm}^{-1}$ and $1536 \mathrm{~cm}^{-1}$, respectively, in the Fourier-transform Infrared (FTIR) spectra of isolated $\mathrm{NC}$, confirmed the removal of appreciable amounts of hemicellulose and lignin components in the OPL fibers. FESEM micrographs revealed the needle-like structures of NC with diameters between $21-24.8 \mathrm{~nm}$. The NC isolation approach presented here offers a promising avenue to ease the use of harsh acids for biomass pretreatment.
\end{abstract}

Keywords: Oil palm leaves, biomass, nanocellulose, Taguchi Orthogonal Design 
hemiselulosa dan lignin dari serat OPL. Mikrograf FESEM mendedahkan struktur NC seperti jarum dengan diameter antara 21-24.8 nm. Pendekatan pengasingan NC yang disediakan di sini menawarkan jalan yang menjanjikan untuk memudahkan penggunaan asid kasar untuk pra-rawatan biomas.

Kata kunci: Daun kelapa sawit, biomas, nanoselulosa, Reka Bentuk Taguchi Ortogonal

(C) 2021 Penerbit UTM Press. All rights reserved

\subsection{INTRODUCTION}

The palm oil industry encompasses a big chunk in both the Indonesian and Malaysian agriculture scenes and the economy. Malaysia being the second world's largest oil palm producer, after Indonesia, is also synonymous with the production of enormous quantities of agricultural biomass [1-3]. Oil palm leaves (OPL), oil palm trunks, palm pressed fibers, and empty fruit bunches make up the palm oil industry's biomass. The rapid expansion of oil palm plantations has contributed to many controversial issues that led to the implementation of Good Agricultural Practices (GAP), especially among the independent oil palm smallholders [4, 5]. The matter has been fueled by widening complications where the agricultural communities in certain regions unscrupulously torch biomass, leading to the precipitous drop in regional air quality. This unhealthy practice serves as a reminder that the full economic prospects of the oil palm biomass as renewable cellulosic materials viz. cellulose, hemicelluloses, and lignin, has yet to be fully explored [6].

Previous works have shown that the cellulosic components from raw OPL can be extracted to fabricate the more valuable nanocellulose (NC) [1, 4, 7]. As a matter of fact, raw OPL is a promising source of NC, which has found applications in different sectors. This boils down to its diminutive size, high specific area (approximately $150 \mathrm{~m}^{2} / \mathrm{g}$ ), and high tensile strength $(7,500 \mathrm{MPa})$, alongside a good degree of crystallinity (>70\%) and transparent appearance [8]. NC can be extracted from plant materials in high quantities using varying types of inorganic acids, such as sulfuric acids and hydrochloric acid $[2,6,7]$. However, the current chemical route to isolate NC from biomass is non-ecofriendly, highly unsustainable, potentially exacerbating current environmental issues. The acidic effluents from the extract process, if not handled properly, can potentially pollute nearby water bodies. The abiotic elements can be severely affected by the harsh acid pollution in water bodies, rendering both surface and underground water inappropriate for use.

That said, the industrial production of NC contributes an insignificant part of the world's economy, despite the all-year-round high availability of cellulosic materials. NC has found applicability in various industries such as food packaging, papermaking, building material, furniture industries, pharmaceutical, automotive, aerospace plants, cosmetics, and innovative green composites [9, 10]. However, the NC-based production economy remains relatively unpopular due to manufacturers having to deal with the impending high costs of downstream processing issues and wastewater treatment [9]. Given these circumstances, a greener way to extract NC from OPL must be found to encourage industrial players to adopt more sustainable manufacturing processes that impact the environment minimally.

An array of extraction methodologies involving enzymes, physical and chemical methods have been explored to extract NC from biomass [6, 10-12]. For instance, enzymes are cleaner degraders of biomass and are less energy-intensive to remove lignin and hemicellulose and leave the cellulose component intact [13]. On the other hand, physical methods that capitalize on the high shear forces may also produce nano-sized cellulose. For example, the continuous acoustic bombardment of electromagnetic waves during ultrasonication ruptures the plant cell wall. The rupture lines increase the surface area along the plant cell walls for the subsequent acids and bases extraction methods. The chemical treatments further digest the polymeric sugar polymers and facilitate the enzymatic attack on the already weakened plant cell wall [14]. In support of a more sustainable approach to isolate NC from raw OPL, this study proposed the combined physical, chemical, and enzymatic treatments. The unified protocol involves an ultrasonic aided extraction (UAE) on powdered OPL followed by enzymatic treatment using a fungal cellulase from a novel Trichoderma asperellum UC1 [15] and, lastly, the acid hydrolysis. It is hypothesized that the unified ternary treatments superficially increase the ruptured lines along the cell walls of OPL. This process facilitates the access of fungal cellulases to the plant cells to degrade lignin and hemicellulose. The last process then sees the acid components finally rid-off the amorphous regions of the remaining cellulosic component. In doing so, lesser quantities of acid are needed in the final purification step.

Hence, this study resorted to the Taguchi Orthogonal array of the Design Expert 7.1.2 software to identify the best processing conditions to favor a more crystalline isolated NC. The statistically-assisted unified $\mathrm{NC}$ isolation process was optimized for parameters, sonication time in ultrasonication process, duration of 
enzymatic digestion, and finally, for two parameters in the acid hydrolysis process involving the concentration of acid and the duration of hydrolysis. It is worth mentioning here that the technique proposed here to isolate NC from OPL remains unreported, and its feasibility remains to be seen. Finally, the morphological characteristics of the isolated NC were characterized.

\subsection{METHODOLOGY}

\subsection{Experimental Design}

In this study, NC was extracted from raw OPL by successive acoustic-, enzyme- and chemical-assisted methods. The extraction parameters were optimized using a response surface technique of the Taguchi Orthogonal array design. The OPL was collected from an oil palm plantation in Universiti Teknologi Malaysia (UTM), and all chemicals used in this study were of analytical grade.

\subsection{Preparation of OPL Powder}

Raw OPLs were first separated from petioles using knives and then sorted, cleaned, cut to smaller pieces, and dried. The samples were then ground using a table grinder (Wellmac RT-08, Taiwan) and sieved through a 300 mesh, and stored in several zip-lock bags until further use.

\subsection{Production of Cellulase by Solid-State Fermentation (SSF) of OPL Powder}

Cellulases used in the enzymatic hydrolysis of OPL was produced by cultivating a novel fungus Trichoderma asperellum UCl under solid-state fermentation (SSF) using raw OPL as the substrate. Fungal spores were harvested using a method by Ang et al. [16] and were enumerated by a hemocytometer. The spores were diluted to an inoculum size of $2.0 \times 10^{8}$ spores $/ g$ of OPL. The SSF process was performed in several $250 \mathrm{~mL}$ Erlenmeyer flasks, where each flask contained $6.0 \mathrm{~g}$ of raw and ground OPL (1.18-3 $\mathrm{mm}$ ) dampened with an appropriate volume of the Mandels production media (pH 5.2) [17]. The flasks containing the production media of modified Mandels medium comprised of $\left(\mathrm{NH}_{4}\right)_{2} \mathrm{SO}_{4}(1.4 \mathrm{~g} / \mathrm{L}), \mathrm{KH}_{2} \mathrm{PO}_{4}(2.0 \mathrm{~g} / \mathrm{L})$, urea $(0.3 \mathrm{~g} / \mathrm{L})$, yeast (1.25g/L), $\mathrm{CaCl}_{2}(0.3 \mathrm{~g} / \mathrm{L}), \mathrm{MgSO}_{4} .7 \mathrm{H}_{2} \mathrm{O}(0.3 \mathrm{~g} / \mathrm{L})$, $\mathrm{FeSO}_{4} .7 \mathrm{H}_{2} \mathrm{O}(0.005 \mathrm{~g} / \mathrm{L}), \mathrm{MnSO}_{4} . \mathrm{H}_{2} \mathrm{O}$ (0.0016 g/L), $\mathrm{ZnSO}_{4} .7 \mathrm{H}_{2} \mathrm{O}(0.0014 \mathrm{~g} / \mathrm{L}), \mathrm{CoCl}_{2}(0.002 \mathrm{~g} / \mathrm{L})$, peptone $(1.0 \mathrm{~g} / \mathrm{L})$ and $2 \mathrm{~mL}$ of Tween 80 . The final moisture level was adjusted to $80 \%$ using a moisture analyzer (MX50, A\&D Weighing Co. Ltd., Japan) before the flasks and the contents were sterilized $\left(121^{\circ} \mathrm{C}, 20\right.$ psi, $\left.20 \mathrm{~min}\right)$. The slurry was inoculated with the standardized spore suspension that was incubated for 7 days at $30^{\circ} \mathrm{C}$.

\subsection{Extraction of Crude Cellulase and Xylanase}

Fermented OPL substrate $(2 \mathrm{~g})$ by $T$. asperellum UC 1 was transferred into $250 \mathrm{~mL}$ Erlenmeyer flasks containing $100 \mathrm{~mL}$ of cold sodium acetate buffer 10.05 $M, \mathrm{pH}$ 5.0). The suspensions were shaken at $250 \mathrm{rpm}$ (28 ${ }^{\circ} \mathrm{C}, 20 \mathrm{~min}$ ) and vortexed at high speed for $1 \mathrm{~min}$, centrifuged (Universal $32 \mathrm{R}$ Hettich Germany) at 2,504 $\times \mathrm{g}, 4^{\circ} \mathrm{C}$ for $20 \mathrm{~min}$. The supernatants were collected and lyophilized to obtain the crude cellulase powder. The enzyme cocktail was used as the crude enzyme source for the SSF. The enzyme was stored at $-20^{\circ} \mathrm{C}$ before its use.

2.5 Taguchi Orthogonal Design Assisted Optimization of Successive Extraction and Isolation of NC from Raw OPL

Isolation of NC from OPL by successive ultrasonication treatments, enzymatic- and chemical extraction was statistically optimized in this study. The statistical design using the Taguchi Orthogonal array of the Design Expert 7.1.2 software of $L_{9}\left(3^{4}\right)$ was employed for minimizing the number of experiments while retaining information of the following processing parameters: (A) sonication time, (B) duration of enzymatic hydrolysis, (C) concentration of acid, and (D) duration of acid hydrolysis. Each variable was tested at three levels (1, 2 , and 3), and the responses were monitored for the highest percentage yield and crystallinity index of the isolated NC. Tables $1 \mathrm{a}$ and $1 \mathrm{~b}$ illustrate the coded values for the three-level-four-factor Taguchi Design and the design variables in the optimization experiment.

Table 1 a) Selected Taguchi Design process parameters and their respective levels and b) design variables used for optimizing the successive processes to isolate NC from raw OPL

\begin{tabular}{|c|c|c|c|c|c|c|}
\hline \multirow[t]{6}{*}{ a) } & \multirow{2}{*}{\multicolumn{3}{|c|}{ Factors }} & \multicolumn{3}{|c|}{ Levels } \\
\hline & & & & -1 & 0 & +1 \\
\hline & \multicolumn{3}{|c|}{ (A)Sonication Time (min) } & 20 & 30 & 40 \\
\hline & \multicolumn{3}{|c|}{ (B)Enzymatic Hydrolysis Duration (h) } & 1 & 3 & 5 \\
\hline & \multicolumn{3}{|c|}{ (C)Acid Concentration (M) } & 6 & 9 & 12 \\
\hline & \multicolumn{3}{|c|}{ (D)Acid Hydrolysis Duration (h) } & 1 & 3 & 5 \\
\hline \multirow[t]{10}{*}{ b) } & Run & A & B & C & & \\
\hline & 1 & 40 & 1 & 12 & & 3 \\
\hline & 2 & 20 & 5 & 12 & & 5 \\
\hline & 3 & 30 & 1 & 9 & & 5 \\
\hline & 4 & 30 & 5 & 6 & & 3 \\
\hline & 5 & 30 & 3 & 12 & & | \\
\hline & 6 & 20 & 3 & 9 & & 3 \\
\hline & 7 & 40 & 3 & 6 & & 5 \\
\hline & 8 & 20 & 1 & 6 & & 1 \\
\hline & 9 & 40 & 5 & 9 & & 1 \\
\hline
\end{tabular}




\subsubsection{Ultrasonication of OPL}

OPL powder $(0.5 \mathrm{~g})$ was transferred into a screwcapped polyethylene bottle containing $5 \mathrm{~mL}$ of distilled water. Each bottle was immersed in a water bath sonicator (Branson 3800), and the content was ultrasonicated $(20,30,40 \mathrm{~min})$ according to specifications (Table $1 \mathrm{~b})$. The sonication process was halted at every 5 min intervals, the mixture was vortexed for $20 \mathrm{~s}$ and then ultrasonicated again. The mixture was left to dry in an oven overnight.

\subsubsection{Enzymatic Hydrolysis}

Enzymatic hydrolysis of the ultrasonicated OPL powder was conducted according to a previous method [15]. The treated OPL sample was transferred to a $250 \mathrm{~mL}$ conical flask containing acetate buffer solution $(50 \mathrm{mM}, \mathrm{pH} 4.8)$, and the sample was incubated in a paraffin oil bath at $50{ }^{\circ} \mathrm{C}$ under different durations $(30,45,60 \mathrm{~min})$ with stirring at 200 $\mathrm{rpm}$. The product was rinsed with copious quantities of distilled water until the $\mathrm{pH}$ of the washings reached neutral. The formed colloidal suspension was centrifuged, and the supernatant was decanted. The suspension was dried to a powder in a $60^{\circ} \mathrm{C}$ oven for $24 \mathrm{~h}$ before acid hydrolysis.

\subsubsection{Acid Hydrolysis}

The acoustic and enzyme-treated OPL sample was transferred into a screw-capped bottle containing acetic acid, sodium chlorite, and distilled water $(0.06$ $\mathrm{mL}: 0.30 \mathrm{~g}: 30 \mathrm{~mL}$ per $1 \mathrm{~g}$ of OPFL). Then, the mixture was refluxed at $85{ }^{\circ} \mathrm{C}$ to remove any remaining hemicellulose and lignin. Next, the suspension was rinsed with excess distilled water till the $\mathrm{pH}$ of the washings reached neutrality. The sample was centrifuged (8500 rpm, $10 \mathrm{~min}$ ) and then oven-dried overnight at $70^{\circ} \mathrm{C}$. According to previously reported methods, the acid hydrolysis process to isolate NC was carried out $[18,19]$ with minor modifications. A suitable ratio of $\mathrm{H}_{2} \mathrm{SO}_{4}$ and treated OPL was mixed and incubated at room temperature under varying durations $(2,4,6 \mathrm{~h})$. The process was halted by washing the suspension repeatedly (20x) in cold distilled water to remove the acid. The mixture was centrifuged (8500 rpm for $10 \mathrm{~min}$ ) and washed again until the washing reached $\mathrm{pH}$ 7.0. The suspension was frozen overnight and lyophilized to obtain the NC.

\subsection{Characterization of Isolated NC}

The isolated NC was characterized by Fourier Transform Infrared-Attenuated Total Reflection (FTIRATR), Field Emission Scanning Electron microscopy (FESEM), and X-ray Diffraction (XRD). The FTIR-ATR spectrum of the isolated NC was analyzed on a Spectrum 100 Series (Perkin Elmer). A small amount of each NC and raw OPL sample was ground thoroughly with potassium bromide, and the resulting powder was pressed onto a transparent pellet using a hydraulic press. The FTIR spectra were obtained in transmission mode between $400 \mathrm{~cm}^{-1}$ and $4000 \mathrm{~cm}^{-1}$ with a resolution of $4 \mathrm{~cm}^{-1}$.

Morphology of the surface and particle size of the isolated NC was examined on a FESEM JEOL JEM-6700F, operating at an accelerating voltage of $5 \mathrm{kV}$ and electric current of $10 \mu \mathrm{A}$. Samples were mounted on the surface of a silicon wafer and sputter-coated with a thin film of gold to prevent charging under the electron beam before examination [6].

The diffractogram pattern for NC was recorded on a powder X-ray diffractometer ( $\mathrm{D} /$ max 2200, Rigaku, Japan) equipped with a $\mathrm{CU}$ Ka radiation source $(\lambda=0.154 \mathrm{~nm})$. The analysis was done at $40 \mathrm{kV}$ and $30 \mathrm{~mA}$. The crystallinity index $\left(I_{\mathrm{c}}\right)$ was calculated from the heights of the 002 peak (loo2, $2 \theta=22^{\circ}$ ), and the intensity minimum was taken between the 002 and 101 peaks $\left(\operatorname{lam}, 2 \theta=15^{\circ}\right)$ using the Segal method [20] (Eqn. 1). The terms looz and lam signify the crystalline and amorphous material, respectively.

$$
I_{c}=(1002-\mathrm{lam}) \times 100
$$

\subsection{RESULTS AND DISCUSSION}

\subsection{Extraction and Isolation of NC from Raw OPL by Crude Enzymes}

The increasing global demand for cellulosedegrading microbial enzymes and the need for cheaper, greener, as well as a sustainable alternative [12] to produce NC from OPL, were the key concerns addressed by this study. SSF using raw OPL as the substrate was used to produce the T. asperellum UC1 cellulose-degrading enzymes. The activity of the enzymes targeted by this study was to hydrolyze the disordered region, namely the amorphous part of the lignocellulose in raw OPL.

The $T$. asperellum strain UCl was fast growing with the mycelia completely covering the entire Petri dish within 6-7 days (Figure 1a and b), forming white fluffy aerial mycelia with concentric white rings that clumped and turned green with conidiation (from the $4^{\text {th }}$ day onwards). The underside of the colony was of the exact color as the growth medium without any obvious pigmentation. Overall, the observed colony patterns were in good agreement with Trichoderma sp. as described in a previous report [21]. The use of SSF to produce cellulase and xylanase by fungal strains $\mathrm{UCl}$ using $\mathrm{OPL}$ as the substrate was also investigated in this study. OPL, which has a high concentration of cellulose and hemicellulose within its fibrillar network [22] can induce the production of fungal cellulolytic enzymes. The crude enzymatic extract obtained in this process was used in the enzymatic treatment for the preliminary extraction of NC from raw OPL. This enzyme's efficiency was measured by monitoring change in the crystallinity of the OPL and assaying 
the total reducing sugar produced by the enzyme after enzymatic treatment of raw OPL.

a)

b)

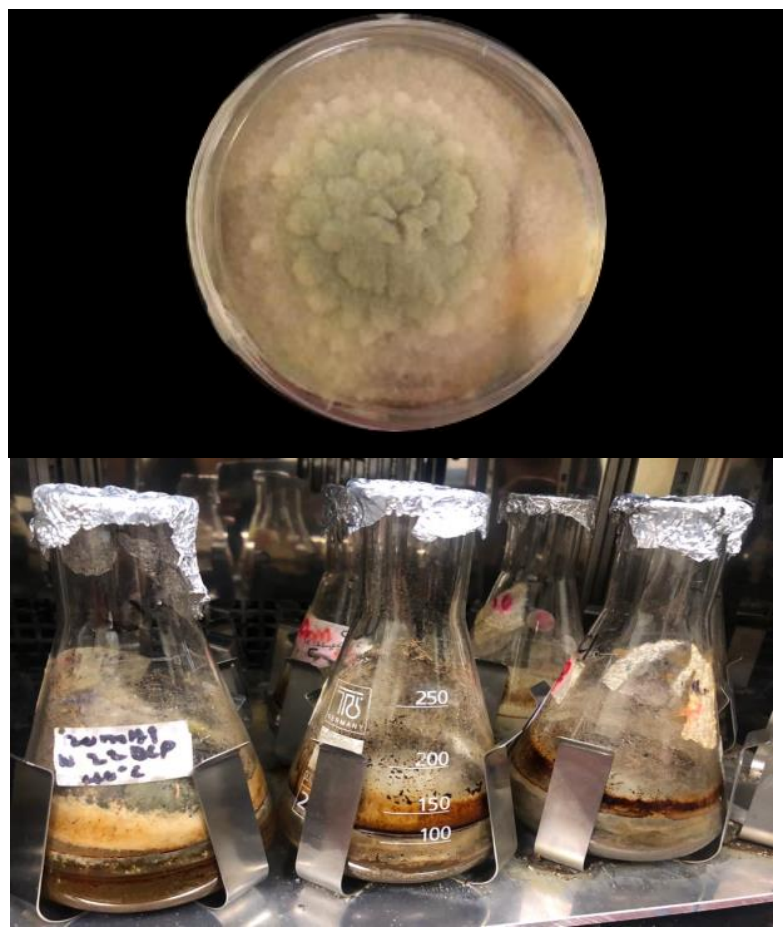

Figure 1 a) The view of $T$. asperellum UC1 and b) cultivation of $T$. asperellum UC1 by SSF of raw OPL to obtain the crude enzyme cocktail for the enzymatic hydrolysis reaction

To isolate NC from raw OPL, the biomass was subjected to successive pretreatments by ultrasonication, enzymatic treatment, and acid hydrolysis. Hence, the optimization process required a total of nine experimental runs of the Taguchi Design to recognize the best-combined extraction parameters to obtain the highest crystallinity of isolated NC. The assessed parameters were sonication time $(20,30,40$ mins), duration of enzymatic treatment $(1,3,5 \mathrm{~h})$, duration of acid hydrolysis $(1,3,5 \mathrm{~h})$, and the concentration of acid $(6,9,12 \mathrm{M})$ (Based on Table 1). NC that was isolated from the successive treatments mentioned above was characterized.

\subsection{Optimization of Successive Extraction of NC using the Taguchi Orthogonal Design}

The best mid-value for each parameter involved in the Taguchi assisted extraction of NC from raw OPL was used for the Taguchi optimization matrix. This part of the study aimed to establish the best independent parameters to maximize isolated NC crystallinity that resulted from the combined processes.

\subsubsection{Statistical Analysis and Model Fitting}

Analysis of Variance (ANOVA) was employed to analyze the orthogonal array design results and determine the influence of four factors on the unified ternary OPL treatment process (Table 2). As it can be seen, the computed model p-value (< 0.0001) revealed the linear model is highly significant $<$ 0.0001 ) at $95 \%$ confidence level with only $0.05 \%$ probability due to noise, and the high F-value (1174.47) corroborates the reliability of the model. All four process parameters of OPL treatment were significant $(p<0.05)$ in impacting the final percentage crystallinity of the isolated NC, where the factors $A, B$ and $C$ being highly significant ( $p$-value < 0.0001 ) to affect the crystallinity of the isolated NC.

Table 2 ANOVA and coefficients of the model

\begin{tabular}{lccccc}
\hline Source & SS* & DF** & MS*** & F-value & p-value \\
\hline Model & 311.23 & 4 & 77.81 & 1174.47 & $<0.0001$ \\
A & 138.24 & 1 & 138.24 & 2086.30 & $<0.0001$ \\
B & 65.34 & 1 & 65.34 & 986.26 & $<0.0001$ \\
C & 1.81 & 1 & 1.81 & 27.40 & 0.0064 \\
D & 105.84 & 1 & 105.84 & 1597.58 & $<0.0001$ \\
Residual & 0.26 & 4 & 0.066 & & \\
Corrected & 311.50 & 8 & & & \\
Total & & & & & \\
\hline
\end{tabular}

*Sum of squares; ${ }^{* *}$ Degree of freedom; ${ }^{* * *}$ Mean square

Of the four factors, sonication time gave the largest impact, as seen from a very large F-value of 2086.30. This was followed by the duration of acid hydrolysis (F-value of 1597.98), the duration of enzymatic treatment ( $F$-value of 986.26), and the least impacting was the concentration of acid during acid hydrolysis treatment (F-value of 27.40). The aforesaid observation was further affirmed by estimating each individual factor's contribution to the OPL treatment process. Sonication time, duration of acid hydrolysis, duration of enzymatic treatment, and acid concentration showed percentage contributions amounting to $44.41 \%, 20.99 \%, 34.00 \%$, and $0.58 \%$, respectively.

The high value of the correlation coefficient $\left(R^{2}=\right.$ 0.9970) of the Taguchi model indicated a good fit with the experimental data (final crystallinity of treated $\mathrm{OPL})$. This was supported by the similar predicted $R^{2}(0.9983)$ and adjusted $R^{2}(0.9958)$, as well as the small differences in deviation $(<0.05 \%)$, thus corroborating the reliability of the model. On top of that, the low value of the coefficient of variance $(0.42 \%)$ in conjunction with the high signal to noise ratio (SNR) of 77.666 signified a well-fitted model alongside an adequate signal to noise ratio. The predicted residual sum of square (PRESS) of 1.37 for each data point indicated a well-fitted design, too (Table 3). The model equation is summarized in Eqn. 2 as follow: 
Crystallinity $(\%)=+59.80-4.80 * \mathrm{~A}+3.30 * \mathrm{~B}-0.55^{*} \mathrm{C}-4.2 * \mathrm{D}$

The above equation can predict and optimize the parameters for the highest crystallinity of isolated NC. This was proven by the close scattering of experimental data near the trend line (Figure 2), an apparent indication of the strong agreement between the experimental and predicted values.

Table 3 Statistical parameters estimated from the ANOVA

\begin{tabular}{ll|ll}
\hline Parameter & Value & Parameter & Value \\
\hline Standard deviation & 0.26 & $R^{2}$ & 0.9970 \\
Mean & 61.90 & Adjusted R2 & 0.9983 \\
Coefficient of variance (\%) & 0.42 & Predicted R2 & 0.9968 \\
PRESS & 1.37 & S/N ratio & 77.666 \\
\hline
\end{tabular}

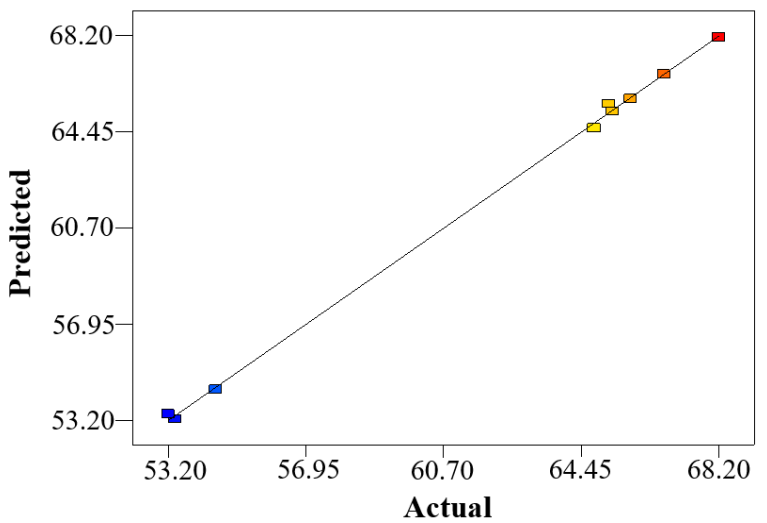

Figure 2 Correlation between actual and predicted values in response to the percentage crystallinity of isolated NC

\subsection{Analysis of Experimental Data}

The experimental conditions for the extraction of nanocellulose from raw OPL must be thoughtfully planned to ensure maximum crystallinity of isolated NC [9, 23]. Results obtained from the experimental design at various extraction conditions were analyzed to observe their effects on the isolated NC's crystallinity. It is important to note that the determination of the cellulose crystallinity by XRD is method-dependent, offering a rough approximation of the crystalline cellulose portion in the entire biomass. It is not the value to be used to assess crystalline against amorphous cellulose portions [24]. Therefore, the values reported in this work should be taken only as a qualitative gauging technique. Table 4 presents the $L_{9}$ orthogonal array experimental design with the mean crystallinity indices.

\subsubsection{Effect of Sonication Time}

The effect of sonication temperature is described to be amongst the most influential parameters to affect the crystallinity of NC isolated from biomass [9].
Literature has shown that any changes in pore structure and dimension by ultrasonication can impact the subsequent hydrolytic reaction rate [24]. In this work, the effect of sonication time was varied at three levels viz. $20 \mathrm{~min}, 30 \mathrm{~min}$, and $40 \mathrm{~min}$ (Figure 3). A clear trend was observed here, wherein a longer sonication time led to a dramatic decrease in the isolated NC's crystallinity. Maximum crystallinity of the isolated NC (68.20\%) was achieved at $20 \mathrm{~min}$ of sonication, followed by $30 \mathrm{~min}(59.6 \%)$ and $40 \mathrm{~min}$ (53.20\%) (Figure 3a). It was apparent that a $20 \mathrm{~min}$ sonication time did not overly degrade the polymer strands into the sugar subunits. The study believed that the shorter ultrasonication duration aided the isolation of the NC by preferentially destroying and removing the amorphous regions in the raw OPL.

On the contrary, further increasing the sonication time only counterproductively produced NC with lower crystallinity due to exacerbated non-selective ultrasonication on the raw OPL. Both the amorphous and crystalline regions were inadvertently degraded in the raw OPL by repetitive shear- and mechanical forces and pressure gradients, generated by the rapid formation and collapse of cavitation bubbles. This increased in kinetic energy also deforms and degrades the plant polymeric structures $[25,26]$ and exposes much of the OPL surface to the subsequent fungal enzymatic attack and $\mathrm{H}_{2} \mathrm{SO}_{4}$. The fungal enzymes were predisposed to digest the OPL and liberate monosaccharides into the surrounding liquid. Likewise, Cui and his coworkers [9] noticed that the crystallinity of NC was sensitive to the ultrasonication duration used in the extraction process. They found a higher degree of the plant polymer decomposed into the main architectural constituents instead of a well-directed removal of the unordered array of amorphous regions with longer sonication duration. Their observation explained the lower crystallinity of the isolated NC with increasing sonication duration.

\subsubsection{Effect of Enzymatic Treatment Duration}

The use of an optimal enzymatic treatment duration can facilitate the isolation of a more crystalline NC [27] to compensate for the drop in enzymatic hydrolysis rate of cellulosic biomass over time [24]. As opposed to the duration of ultrasonication treatment (Section 3.3.1), it was apparent that a prolonged enzymatic treatment exerted an appreciable positive effect on the crystallinity of the isolated NC. Maximum crystallinity was attained after $5 \mathrm{~h}$ of incubation (68.20\%) and declined with shorter incubation times of $3 \mathrm{~h}(59.5 \%)$ and $1 \mathrm{~h}$ (56.8 \%). The notable monotonic increase in the isolated NC crystallinity with time seen here could be interpreted as an increase in the preferential hydrolysis of amorphous cellulose over crystalline cellulose by the fungal enzymes, aside from hydrolyzing the hemicellulose components (Figure 3b) [24].

Given enough time, the fungal cellulases could cleave the glycosidic bonds in the cellulose of OPL without altering the crystalline structure. This is the key 
feature of fungal cellulases that this study is harnessing. The higher crystallinity of isolated NC with increasing incubation time correlated with the natural enzymatic processes that require longer incubation time to hydrolyze the cellulose, compared to non-enzymatic processes [23]. It is a trade-off for a greener and sustainable approach compared to the speed of a process to transform the unwanted biomass into versatile nanomaterials. Based on the findings, a longer incubation time for the enzymatic degradation of the ultrasonically treated OPL may further improve the isolated NC's crystallinity.

Table $4 \mathrm{~L}_{9}$ orthogonal array experimental design with the mean crystallinity indices

\begin{tabular}{|c|c|c|c|c|c|c|}
\hline \multirow[b]{2}{*}{ Standard } & \multicolumn{4}{|c|}{ Parameters } & \multicolumn{2}{|c|}{ Crystallinity (\%) } \\
\hline & $\begin{array}{c}\text { Sonication Time } \\
\text { (min) }\end{array}$ & $\begin{array}{c}\text { Duration of Enzymatic } \\
\text { Treatment }(\mathrm{h})\end{array}$ & $\begin{array}{l}\text { Concentration of } \\
\text { Acid (M) }\end{array}$ & $\begin{array}{l}\text { Duration of Acid } \\
\text { Hydrolysis (h) }\end{array}$ & Actual & Predicted \\
\hline 1 & $40(+1)$ & $1(-1)$ & $12(+1)$ & $3(0)$ & 53.40 & 53.25 \\
\hline 2 & $20(-1)$ & $5(+1)$ & $12(+1)$ & $5(+1)$ & 65.30 & 65.25 \\
\hline 3 & $30(0)$ & $1(-1)$ & $9(0)$ & $5(+1)$ & 54.50 & 54.40 \\
\hline 4 & $30(0)$ & $5(+1)$ & $6(-1)$ & $3(0)$ & 65.80 & 65.75 \\
\hline 5 & $30(0)$ & $3(0)$ & $12(+1)$ & $1(-1)$ & 65.20 & 65.55 \\
\hline 6 & $20(-1)$ & $3(0)$ & $9(0)$ & $3(0)$ & 66.70 & 66.70 \\
\hline 7 & $40(+1)$ & $3(0)$ & $6(-1)$ & $5(+1)$ & 53.20 & 53.45 \\
\hline 8 & $20(-1)$ & $1(-1)$ & $6(-1)$ & $1(-1)$ & 68.20 & 68.15 \\
\hline 9 & $40(+1)$ & $5(+1)$ & $9(0)$ & $1(-1)$ & 64.80 & 64.60 \\
\hline
\end{tabular}

a)

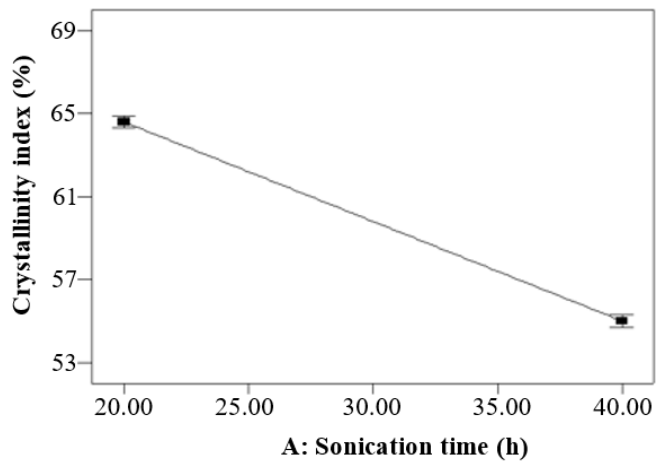

c)

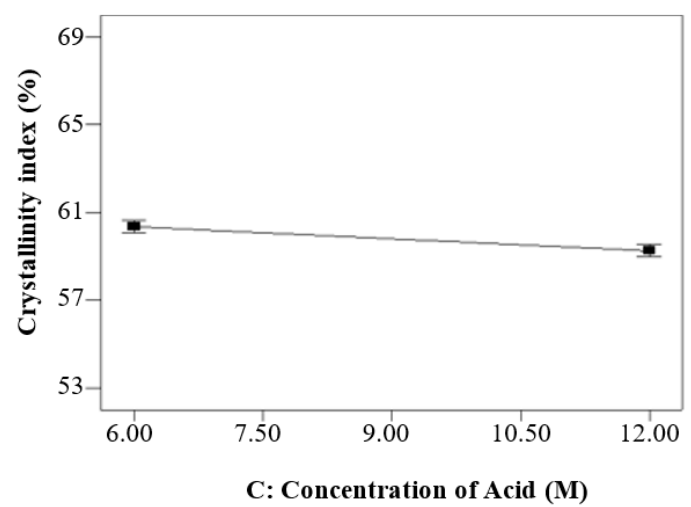

b)

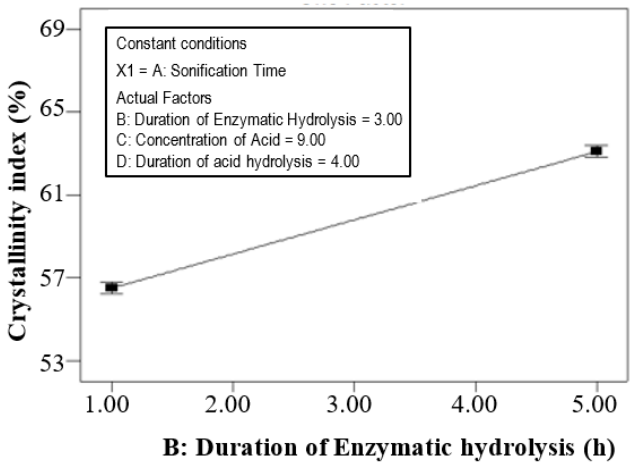

d)

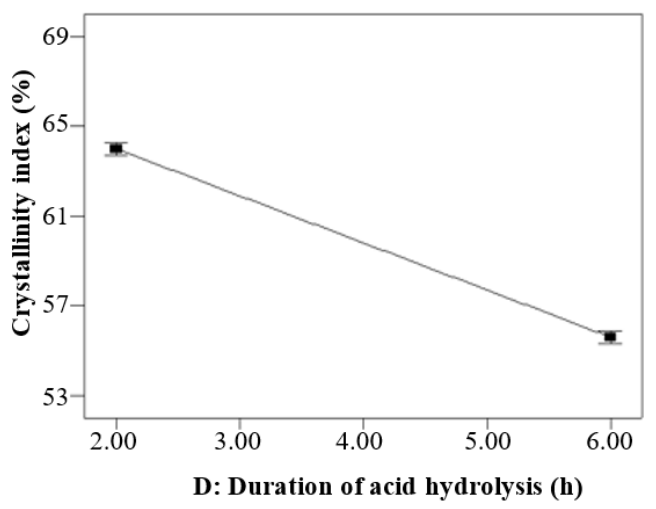

Figure 3 The effect of a) duration of sonication, b) duration of enzymatic treatment, c) acid concentration and d) acid hydrolysis duration on the crystallinity of isolated NC from the unified acoustic, enzymatic- and chemical-assisted treatment of raw OPL 
Moreover, the resulting digestion of the acoustically treated OPL helps eliminate impurities by solubilizing hemicelluloses and lignin into the surrounding supernatant. These impurities are then removed during the rinsing process before purified cellulose fibers are acquired [28, 29].

\subsubsection{Effect of Acid Concentration}

The transformation of cellulose into NC is also affected by the concentration of acid during the pretreatment of OPL [7]. The study examined the effect of acid concentration varied at three levels, i.e. $6 \mathrm{M}, 9 \mathrm{M}$, and $12 \mathrm{M}$, and the results are depicted in Figure 3c. However, it is worth mentioning here that only acid concentrations between 6-9 M were investigated as this is the range typically seen in the literature to extract cellulose from lignocellulosic materials. The $6 \mathrm{M} \mathrm{H}_{2} \mathrm{SO}_{4}$ treatment produced $\mathrm{NC}$ with $60.20 \%$ crystallinity. Further increases in acid concentrations marginally reduced the crystallinity of isolated $\mathrm{NC}$ to $59.2 \%$ at $12 \mathrm{M}$ of the acid. This also proved that $\mathrm{NC}$ is better isolated from raw OPL under a milder acidic condition. A plausible explanation has to do with chlorine dioxide liberated from the acidification of sodium chlorite, which attacked the lignin's interfering phenolic group. Such a reaction destroyed the structural linkages between the lignin and carbohydrate. The reaction disrupts the lignin structure by breaking the glycosidic ether bonds and eliminating this component from OPFL [30].

In terms of the process's economics and sustainability, an acid-assisted degradation of OPL is best carried out at the lowest possible acid concentration [31]. The effective isolation of NC at 6 $M$ seen here may have to do with the disordered amorphous regions being more susceptible to the acid hydrolysis process than the crystalline regions. Furthermore, dilute acids gradually cleave the amorphous cellulose regions to promote the isolation of more crystalline NC. Instead, highly concentrated acids tend to exert greater damage to the crystalline regions during the hydrolysis process and yields NCs with lower crystallinity indices [32]. Hence, the findings were seen to support earlier reports that a less concentrated acid treatment is better for isolating a more crystalline NC.

\subsubsection{Effect of Acid Hydrolysis Duration}

The factor of the duration of acid hydrolysis in the experiment was assessed at three levels $(1,3$, and 5 h). Results showed that $2 \mathrm{~h}$ was optimal in yielding the highest crystallinity of isolated NC at $68.20 \%$. Further increasing the reaction time steadily caused a decline in NC crystallinity that reached the lowest point at 53.20\% after $6 \mathrm{~h}$ (Figure 3d). Observably, a shorter reaction time was effective in producing a more crystalline NC. A longer acid incubation time only heightened the likelihood of the counterproductive non-selective hydrolysis of the crystalline regions of cellulose [33]. This caused the OPL polymeric structures to be undesirably fractionated into simple sugars instead of the shortrange ordered polysaccharides that shape the basic construct of NC. Likewise, the longer reaction time also degraded the crystalline portion of cellulose and decreased the isolated NC crystallinity. While acid hydrolysis generally positively affects isolated NC crystallinity, extending the treatment duration is economically unsavory. It could adversely influence the final quality of NC isolated from raw OPL.

\subsection{Characterization of Isolated NC from OPL}

The study found that delignified and dehemicellulosified OPL has a whitish appearance, a qualitative indication of the richer cellulosic material in the final product (Figure 4). This outcome was consistent with the considerable absence of both lignin and hemicellulose before pure cellulose can be extracted from raw OPL to produce crystalline NC. This is because the "wax-like" properties of the two components tend to impede the hydronium ions in $\mathrm{H}_{2} \mathrm{SO}_{4}$ to protonate the ether bonds in the glycosidic chains. Hence, the consequent treatment of the semi-purified cellulose fibers with concentrated $\mathrm{H}_{2} \mathrm{SO}_{4}$ was crucial to break down the glycosidic bonds and then convert them into smaller units of $\mathrm{NC}$ in the enzyme treatment process. In this process, the $\mathrm{H}_{2} \mathrm{SO}_{4}$ and hydroxyl groups in cellulose undergo esterification to form anionic sulfate ester groups on the NC surface [34, 35]. The negatively charged sulfate ester groups present on the NC's surface are generally useful in promoting better dispersion of $\mathrm{NC}$ through mutual nucleophilic repulsions [36]. The general $\mathrm{H}_{2} \mathrm{SO}_{4}$ reaction on cellulose was crucial in removing the remaining amorphous regions in the biopolymer [36, 37]. It is important to emphasize here that the isolation of NC from raw OPL by the proposed unified protocol used a considerably lesser amount of $\mathrm{H}_{2} \mathrm{SO}_{4}$.

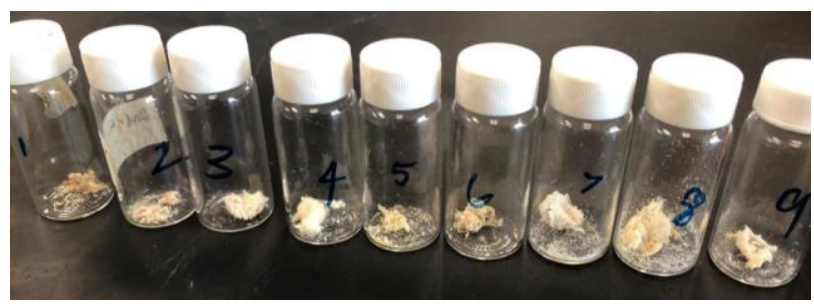

Figure $4 \mathrm{NC}$ isolated from raw OPL after successive acoustic, enzymatic and chemical treatments

\subsubsection{FTIR Spectroscopy: Attenuated Total Reflection (FTIR-ATR)}

In this study, the FTIR-ATR analysis was done to identify the functional groups present in raw OPL and the isolated NC and monitor chemical changes in the samples after each treatment. Table 5 summarizes the FTIR-ATR results, while the spectra for the raw OPL and isolated NC are shown in Figures $5 a$ and $5 b$, respectively. In Figure 5a, a peak observed at 1734 
$\mathrm{cm}^{-1}$ in the untreated OPF was likely to be associated with the $\mathrm{C}=\mathrm{O}$ stretching of either acetyl and uronic ester groups of hemicelluloses or possibly the carboxylic groups found on ferulic and p-coumeric acids of lignin [34]. Peaks that emerged at $1635 \mathrm{~cm}^{-1}$ and $1517 \mathrm{~cm}^{-1}$ can be assigned to the vibration of $\mathrm{C}=\mathrm{C}$ bonds in the benzene ring of lignin [38]. Additionally, the lignin characteristic peak at 1462 $\mathrm{cm}^{-1}$ and $1200 \mathrm{~cm}^{-1}$ were observed as the presence of methoxy $\mathrm{O}-\mathrm{CH}_{3}$ and $\mathrm{C}-\mathrm{O}-\mathrm{C}$ stretching of the aryl-alkyl ether group, respectively [7].

The absorption peaks located between 3288-3332 $\mathrm{cm}^{-1}$ and 2849-2917 $\mathrm{cm}^{-1}$ in both spectra were attributed to the stretching vibrations of $-\mathrm{OH}$ groups and aliphatic saturated $\mathrm{C}-\mathrm{H}$, respectively. Characteristic stretching vibrations between 1020-1032 $\mathrm{cm}^{-1}$ and $664-614 \mathrm{~cm}^{-1}$ corresponded to those of the pyranose ring and glycosidic linkages between glucose units in cellulose [39]. Notably, peaks for the bending of $-\mathrm{OH}$ groups observed at 1633-1635 $\mathrm{cm}^{-1}$ were believably due to the adsorption of water within the biopolymer [37].

a)

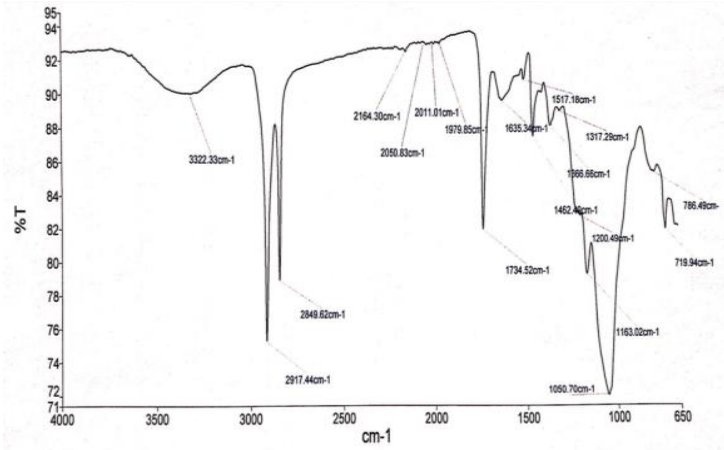

b)

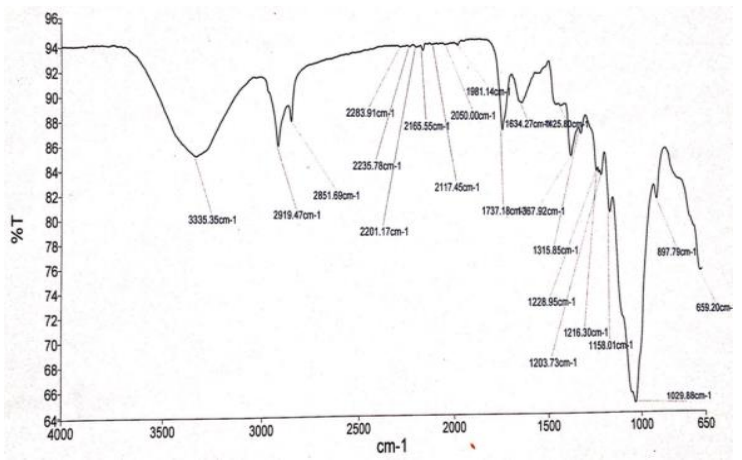

Figure 5 FTIR-ATR spectra of a) raw OPL and b) isolated NC obtained after successive treatments

Figure $5 b$ revealed striking differences in the spectra of isolated NC compared to the untreated raw OPL fiber (Figure 5a). It appears that the successive physical, enzymatic and chemical treatments had somewhat changed the composition and the ordered degree of the cellulosic component in the treated sample. Peak intensities of the $\mathrm{C}=\mathrm{O}$ and $C=C$ peaks for hemicellulose and lignin in the treated OPL were noteworthily diminished. The results seen here conveyed the considerably reduced contents of both hemicellulose and lignin components in the isolated NC (Figure 5b). Such a change was a strong description of reduced lignin content as well as reduced organic matter in the successively treated OPL sample.

Meanwhile, increased peak intensities between 1029-1634 $\mathrm{cm}^{-1}$ were implicative of the qualitative enhancement in the degree of order of the cellulosic component (Table 5). Based on the cumulative findings, the study could interpret that the successive treatments had transformed the native cellulose I in the raw OPL into cellulose II in the isolated NC.

Table 5 FTIR-ATR spectra of a) raw OPL and b) isolated NC

\begin{tabular}{ll}
\hline \multicolumn{1}{c}{ Functional Groups } & Wavenumber $\left(\mathbf{c m}^{-1}\right)$ \\
\hline Raw OPL & \\
$\mathrm{C}=\mathrm{O}$ & 1734 \\
$\mathrm{C}=\mathrm{C}$ & 1635 and 1517 \\
$\mathrm{O}-\mathrm{CH}_{3}$ and $\mathrm{C}-\mathrm{O}-\mathrm{C}$ & 1462 and 1200
\end{tabular}

Isolated NC

$\begin{array}{ll}\mathrm{C}=\mathrm{O} \text { (reduced intensity) } & 1737 \\ \mathrm{C}=\mathrm{C} \text { (reduced intensity) } & 1634 \text { and } 1525 \\ \mathrm{O}-\mathrm{CH}_{3} \text { and } \mathrm{C}-\mathrm{O}-\mathrm{C} \text { (increased } & 1469 \text { and } 1203\end{array}$

intensity)

\subsubsection{X-ray Diffraction}

Table 4 depicts the value of crystallinity obtained from X-ray diffractograms of OPL and all nine experimental runs to isolate NC using the unified ternary treatment. Comparing the diffractograms of cellulose and $\mathrm{NC}$, it was clearly revealed that the higher intensity of the NC peak at $2 \theta=12^{\circ}$ (110) was assigned to the crystalline structure of cellulose type I. In contrast, the doublet peaks at $2 \theta=21^{\circ}$ (110) and $2 \theta=22^{\circ}(002)$, attributed to the amorphous structure of cellulose, were better resolved. The outcome signified that NC was present after cellulase and xylanase treatments. Consequently, the crystallinity of the isolated NC also improved over the raw OPL (Figure 6a). NC produced from run 8 (Figure 6b) exhibited the highest crystallinity index at $68.2 \%$, while NC produced from run 7 recorded the lowest reading at $53.20 \%$. The improvement in crystallinity of the enzymatically treated OPL between 14.8-29.8\%, seen in this study, resulted from the splitting of cellulose glycosidic groups into smaller anhydroglucose units. This led to the elevated percentage of crystallinity in the treated OPL to give the NC, as compared to raw OPL before the SSF process.

Moreover, the natural action of the fungal enzymes used in this study had likely cleaved and liberated most of the amorphous domains in the lignocellulose of OPL as free sugar molecules. For the most part, this action left the crystalline, long-range 
ordered array of isolated cellulose in OPL intact, proven by the incremental rise in crystallinity indices of treated OPL. The data seen here is consistent with a report by Aditiawati et al. [40], which investigated the efficiency of cellulose and xylanase in enhancing the crystallinity of treated oil palm empty fruit bunch (OPEFB). The fungal cellulolytic enzyme was found to cleave the amorphous region, and crystallinity was further increased with the ensuing mechanical treatment on the biomass. The raw OPEFB showed an improved crystallinity from $26.55 \%$ to $76.15 \%$ in the enzymatically treated biomass, in efforts to isolate the NC.

\subsubsection{Field Emission Spectroscopy (FESEM)}

FESEM micrographs of the optimized Taguchi Designassisted treatment on the raw OPL are shown in Figure 7. The treated OPL extracted from run 8 was chosen for the subsequent FESEM analysis, in view of its highest crystallinity compared to other runs.

As can be seen, the NC obtained from the treated OPL appeared somewhat more uniformly distributed and exhibited needle-like structures with diameters ranging between 21.0-24.8 $\mathrm{nm}$. The observably coarser surface of the NC isolated in this study can be attributed to the dissolution of lignin during the rinsing process, ensuing the two cycles of chemical treatments. Thus, the study's findings support previous observations by Mohaiyiddin et al. [34] and Elias et al. [7], which described seeing a coarser needle-like surface of NC after successful isolations from plant biomass. In this study, the attained needle-like structure of the NC in run 8 matched morphologies of earlier reported NCs purified by a final acid hydrolysis treatment.

a)

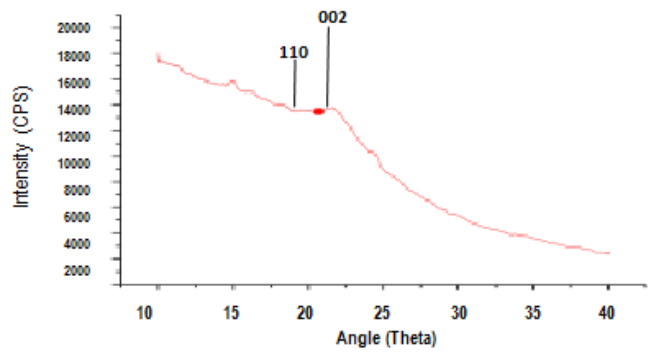

b)

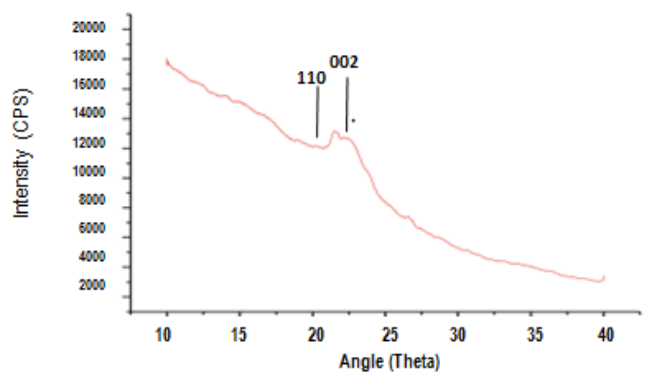

Figure 6 X-ray diffractogram of a) OPL before SSF and b) NC isolated from run 8
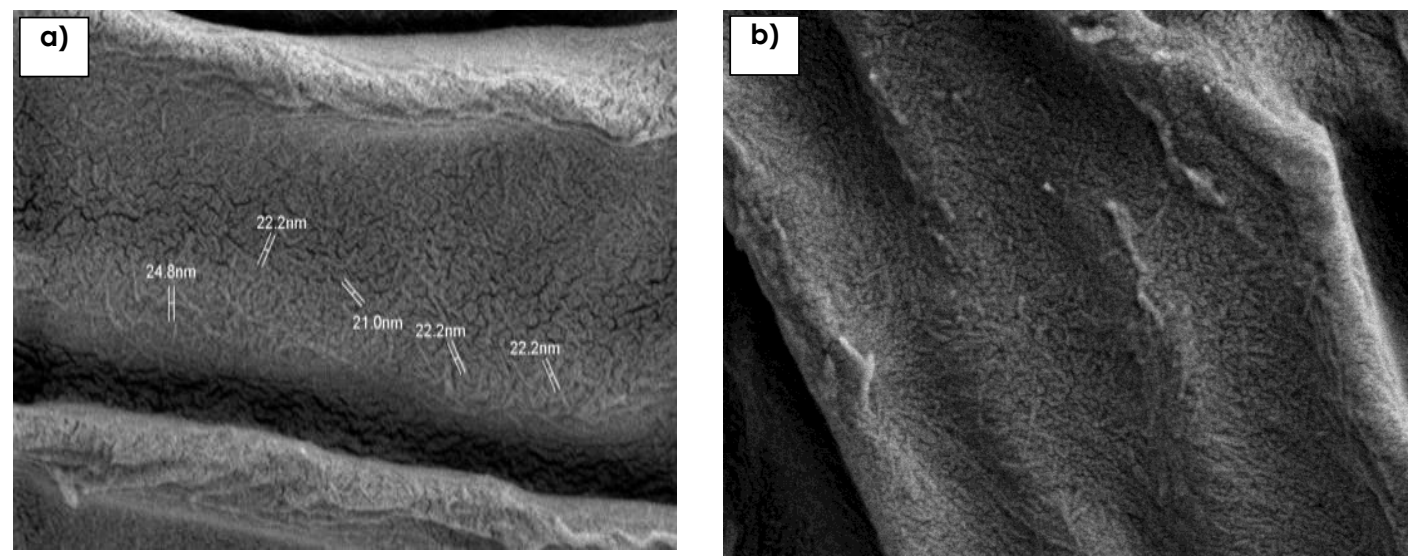

Figure 7 FESEM micrographs of the isolated NC obtained from the Taguchi Designed optimized process at a) $40000 x$ and b) $50000 x$ magnification, respectively

\subsection{CONCLUSION}

In this study, the parameters viz. sonication time, enzymatic digestion duration, acid hydrolysis duration, and acid concentration that favored the high yield extraction of NC from raw OPL were successfully optimized by the Taguchi Orthogonal Design. The best conditions that gave the highest crystallinity (68.2\%) were established as $20 \mathrm{~min}$ of sonication, $1 \mathrm{~h}$ of hydrolysis, $6 \mathrm{M}$ of acid, and $1 \mathrm{~h}$ of acid hydrolysis. X-ray diffractograms revealed that the extracted NC from run 8 gave the highest crystallinity index (68.2\%) while the lowest came from run 7 (53.2\%). The FTIR spectra revealed that much of the hemicellulose and lignin components were removed during bleaching and acid hydrolysis, 
based on reduced peaks at $1734 \mathrm{~cm}^{-1}$ and $1536 \mathrm{~cm}^{-1}$ for $\mathrm{C}=\mathrm{O}$ and $\mathrm{C}=\mathrm{C}$. The isolated NCs were needle-like structures in FESEM micrographs, with diameters between 21-24.8 $\mathrm{nm}$. Hence, it can be construed that the integration of acoustic and enzymatic treatments is a promising greener approach to prepare moderately crystalline NC from raw OPL. The findings also demonstrated this strategy's capability to negate the non-eco-friendly conventional means to isolate NC from biomass. This new protocol is also a more benign means to extract NC from discarded agricultural biomass.

\section{Acknowledgment}

This work was supported by the High Impact Research Grant awarded by the Universiti Teknologi Malaysia, Johor (Q.J130000.2454.08G45).

\section{References}

[1] N. Elias, S. Chandren, F. I. A. Razak, J. Jamalis, N. Widodo, and R. A. Wahab. 2018. Characterization, Optimization and Stability Studies on Candida rugosa Lipase Supported on Nanocellulose Reinforced Chitosan Prepared from Oil Palm Biomass. International Journal of Biological Macromolecules. 114:306-316. DOI: http://dx.doi.org/10.1016/j.jibiomac.2018.03.095.

[2] E. Onoja, S. Chandren, F. I. Abdul Razak, N. A. Mahat, and R. A. Wahab. 2019. Oil Palm (Elaeis guineensis) Biomass in Malaysia: The Present and Future Prospects. Waste and Biomass Valorization. 10(8): 2099-2117.

DOl: http://dx.doi.org/10.1007/s12649-018-0258-1.

[3] U. R. Ezeilo, R. A. Wahab, L. C. Tin, I. I. Zakaria, F. Huyop, and N. A. Mahat. 2019. Fungal-assisted Valorization of Raw Oil Palm Leaves for Production of Cellulase and Xylanase in Solid State Fermentation Media. Waste and Biomass Valorization. 11: 3133-3149.

DOI: http://dx.doi.org/10.1007/s12649-019-00653-6.

[4] N. Elias, R. A. Wahab, S. Chandren, J. Jamalis, N. A. Mahat, and L. W. Jye. 2020. Structure and Properties of Lipase Activated by Cellulose-silica Polyethersulfone Membrane for Production of Pentyl Valerate. Carbohydrate Polymers. 245: 116549.

DOI: http://dx.doi.org/10.1016/j.carbpol.2020.116549.

[5] I. Jelsma, L.S. Woittiez, J. Ollivier, and A.H. Dharmawan. 2019. Do Wealthy Farmers Implement Better Agricultural Practices? An Assessment of Implementation of Good Agricultural Practices among Different Types of Independent Oil Palm Smallholders in Riau, Indonesia. Agricultural Systems. 170: 63-76.

DOI: https://doi.org/10.1016/j.agsy.2018.11.004.

[6] E. Onoja, S. Chandren, F. I. A. Razak, and R. A. Wahab. 2018. Extraction of Nanosilica from Oil Palm Leaves and Its Application as Support for Lipase Immobilization. Journal of Biotechnology. 283(5): 81-96. DOI: http://dx.doi.org/10.1016/j.jbiotec.2018.07.036.

[7] N. Elias, S. Chandren, N. Attan, N. A. Mahat, F. I. A. Razak J. Jamalis, and R. A. Wahab. 2017. Structure and Properties of Oil Palm-based Nanocellulose Reinforced Chitosan Nanocomposite for Efficient Synthesis of Butyl Butyrate. Carbohydrate Polymers. 176: 281-292.

DOI : http://dx.doi.org/10.1016/j.carbpol.2017.08.097.

[8] P. Thomas, T. Duolikun, N. P. Rumjit, S. Moosavi, C. W. Lai, M. R. B. Johan, and L. B. Fen. 2020. Comprehensive Review on Nanocellulose: Recent Developments, Challenges and
Future Prospects. Journal of the Mechanical Behavior of Biomedical Materials. 110: 103884

DOI: http://dx.doi.org/10.1016/j.jmbbm.2020.103884.

[9] S. Cui, S. Zhang, S. Ge, L. Xiong, and Q. Sun. 2016. Green Preparation and Characterization of Size-controlled Nanocrystalline Cellulose Via Ultrasonic-assisted Enzymatic Hydrolysis. Industrial Crops and Products. 83(5): 346-352. DOI: http://dx.doi.org/10.1016/j.indcrop.2016.01.019.

[10] Y. W. Chen, and H. V. Lee. 2018. Revalorization of Selected Municipal Solid Wastes as New Precursors of "Green" Nanocellulose Via a Novel One-pot Isolation System: A Source Perspective. International Journal of Biological Macromolecules. 107(4): 78-92. DOI : http://dx.doi.org/10.1016/j.jibiomac.2017.08.143.

[11] V. Alvarez, and A. Vázquez. 2004. Thermal Degradation of Cellulose Derivatives/Starch Blends and Sisal Fibre Biocomposites. Polymer Degradation and Stability. 84(1): 13-21.

DOI: http://dx.doi.org/10.1016/j.polymdegradstab.2003. 09.003 .

[12] M. Henriksson, G. Henriksson, L. Berglund, and T. Lindström. 2007. An Environmentally Friendly Method for EnzymeAssisted Preparation of Microfibrillated Cellulose (MfC) Nanofibers. European Polymer Journa. 43(8): 3434-3441. DOI : http://dx.doi.org/10.1016/j.eurpolymj.2007.05.038.

[13] M. L. Hassan, J. Bras, E. A. Hassan, C. Silard, and E. Mauret. 2014. Enzyme-assisted Isolation of Microfibrillated Cellulose from Date Palm Fruit Stalks. Industrial Crops and Products. 55(7): 102-108.

DOI : http://dx.doi.org/10.1016/j.indcrop.2014.01.055.

[14] Q. Song, W. T. Winter, B.M. Bujanovic, and T. E. Amidon. 2014. Nanofibrillated Cellulose (NFC): A High-value CoProduct that Improves the Economics of Cellulosic Ethanol Production. Energies. 7(2): 607-618. DOI: http://dx.doi.org/10.3390/en7020607.

[15] U. R. Ezeilo, R. A. Wahab, and N. A. Mahat. 2019. Optimization Studies on Cellulase and Xylanase Production by Rhizopus oryzae UC2 using Raw Oil Palm Frond Leaves as Substrate Under Solid State Fermentation. Renewable Energy. 156: 1301-1312. DOI: $\mathrm{http}$ ://dx.doi.org/10.1016/j.renene.2019.11.149.

[16] S. Ang, E. Shaza, Y. Adibah, A. Suraini, and M. Madihah. 2013. Production of Cellulases and Xylanase by Aspergillus fumigatus SK 1 using Untreated Oil Palm Trunk through Solid State Fermentation. Process Biochemistry. 48(9): 12931302.

DOI: http://dx.doi.org/10.1016/j.procbio.2013.06.019.

[17] M. Mandels, and J. Weber. 1969. The Production of Cellulases. In: G. Hajny (Ed.). Cellulases and Their Applications. American Chemical Society, Washington, DC. 391-414. DOl: http://dx.doi.org/10.1021/ba-1969-0095.ch023.

[18] P. Phanthong, P. Reubroycharoen, X. Hao, G. XU, A. Abudula, and G. Guan. 2018. Nanocellulose: Extraction and Application. Carbon Resources Conversion. 1(1): 3243. DOI: http://dx.doi.org/10.1016/j.crcon.2018.05.004.

[19] E. Onoja, S. Chandren, F. I. A. Razak, and R. A. Wahab. 2018. Enzymatic Synthesis of Butyl Butyrate by Candida Rugosa Lipase Supported on Magnetized-nanosilica from Oil Palm Leaves: Process Optimization, Kinetic and Thermodynamic Study. Journal of the Taiwan Institute of Chemical Engineers. 91: 105-1 18. DOI: http://dx.doi.org/10.1016/j.jtice.2018.05.049.

[20] L. Segal, J. Creely, A. Martin Jr, and C. Conrad. 1959. An Empirical Method for Estimating the Degree of Crystallinity of Native Cellulose using the X-ray Diffractometer. Textile Research Journal. 29(10): 786-794. DOI: http://dx.doi.org/10.1177/004051755902901003.

[21] T. M. Abdel-Ghany, M. Ganash, M. M. Bakri, and A. M. AlRajhi. 2018. Molecular Characterization of Trichoderma Asperellum and Lignocellulolytic Activity on Barley Straw Treated with Silver Nanoparticles. BioResources. 13(1): 1729-1744. 
DOI: http://dx.doi.org/10.15376/biores.13.1.1729-1744

[22] T. C. D. Santos, G. Abreu Filho, A. R. D. Brito, A. J. V. Pires, R. C. F. Bonomo, and M. Franco. 2016. Production and Characterization of Cellulolytic Enzymes by Aspergillus niger and Rhizopus sp. by Solid State Fermentation of Prickly Pear. Revista Caatinga. 29(1): 222-233. DOI: http://dx.doi.org/10.1590/1983-21252016v29n126rc.

[23] C.-Q. Ruan, Z. Wang, J. Lindh, and M. Strømme. 2018. Carbonized Cellulose Beads for Efficient Capacitive Energy Storage. Cellulose. 25(6): 3545-3556. DOI: http://dx.doi.org/10.1039/C3CC40324F.

[24] K. Kafle, H. Shin, C. M. Lee, S. Park, and S. H. Kim. 2015. Progressive Structural Changes of Avicel, Bleached Softwood and Bacterial Cellulose During Enzymatic Hydrolysis. Scientific Reports. 5(1): 1-10. DOI: http://dx.doi.org/10.1038/srep15102.

[25] M. Mohsin, N. Sarwar, S. Ahmad, A. Rasheed, F. Ahmad, A. Afzal, and S. Zafar. 2016. Maleic Acid Crosslinking of C-6 Fluorocarbon as Oil and Water Repellent Finish on Cellulosic Fabrics. Journal of Cleaner Production. 112 3525-3530.

DOI: http://dx.doi.org/10.1016/j.jclepro.2015.10.045

[26] H. Zhao, J. Li, and K. Zhu. 2018,. Bacterial Cellulose Production from Waste Product and Fermentation Conditions Optimization. IOP Conference Series: Materials Science and Engineering. 022041. DOI: http://dx.doi.org/10.1088/1757-899X/394/2/022041.

[27] L. Camargo, S. Pereira, A. Correa, C. Farinas, J. Marconcini, and L. Mattoso. 2016. Feasibility of Manufacturing Cellulose Nanocrystals from the Solid Residues of Second-generation Ethanol Production from Sugarcane Bagasse. BioEnergy Research. 9(3): 894-906. DOI: http://dx.doi.org/10.1007/s12155-016-9744-0.

[28] J. Wetterling. 2012. Modelling of Hemicellulose Degradation during Softwood Kraft Pulping. Department of Chemical and Biological Engineering. Chalmers University of Technology. 77.

DOI: https://odr.chalmers.se/bitstream/20.500.12380/1608 35/1/160835.pdf

[29] D. H. Lee, C. H. Park, J. M. Yeo, and S. W. Kim. 2006. Lipase Immobilization on Silica Gel Using a Cross-linking Method. Journal of Industrial and Engineering Chemistry. 12(5): 777782.

DOI: https://pdfs.semanticscholar.org/33da/b58a42670ec f2728b8505c37109dfb55800e.pdf.

[30] M. Taherdanak, and H. Zilovei. 2014. Improving Biogas Production from Wheat Plant Using Alkaline Pretreatment. Fuel. 115: 714-719.

DOl: http://dx.doi.org/10.1016/j.fuel.2013.07.094

[31] P. Phanthong, G. Guan, Y. Ma, X. Hao, and A. Abudula. 2016. Effect of Ball Milling on the Production of Nanocellulose Using Mild Acid Hydrolysis Method. Journal of the Taiwan Institute of Chemical Engineers. 60: 617-622.
DOI: http://dx.doi.org/10.1016/j.jtice.2015.11.001.

[32] W. Wulandari, A. Rochliadi, and I. Arcana. 2016. Nanocellulose Prepared by Acid Hydrolysis of Isolated Cellulose from Sugarcane Bagasse. IOP Conference Series: Materials Science and Engineering. IOP Publishing. 012045.

DOI: http://dx.doi.org/10.1088/1757-899X/107/1/012045

[33] A. Shalini, K. Pandian, and V. Jaisankar. 2017. Synthesis, Characterization of Polyaniline and Polyaniline Encapsulated Cellulose Isolated from Sugarcane Bagasse and Its Study on Electronic Properties. DJ Journal of Engineering Chemistry and Fuel. 2(1): 61-66. DOI: http://dx.doi.org/10.18831/djchem.org/201701 1007.

[34] M. S. Mohaiyiddin, O. H. Lin, W. T. Owi, C. H. Chan, C. H. Chia, S. Zakaria, and H. M. Akil. 2016. Characterization of Nanocellulose Recovery from Elaeis Guineensis Frond for Sustainable Development. Clean Technologies and Environmental Policy. 18(8): 2503-2512. DOI: http://dx.doi.org/10.1007/s10098-016-1191-2.

[35] A. Dufresne. 2013. Nanocellulose: A New Ageless Bionanomaterial. Materials Today. 16(6): 220-227. DOI: http://dx.doi.org/10.1016/j.mattod.2013.06.004

[36] P. P. Zhang, D. S. Tong, C. X. Lin, H. M. Yang, Z. K. Zhong, W. H. Yu, H. Wang, and C. H. Zhou. 2014. Effects of Acid Treatments on Bamboo Cellulose Nanocrystals. Asia-Pacific Journal of Chemical Engineering. 9(5): 686695.

DOI: http://dx.doi.org/10.1002/apj.1812.

[37] B. Deepa, E. Abraham, N. Cordeiro, M. Mozetic, A. P. Mathew, K. Oksman, M. Faria, S. Thomas, and L. A. Pothan. 2015. Utilization of Various Lignocellulosic Biomass for the Production of Nanocellulose: A Comparative Study. Cellulose. 22(2): 1075-1090.

DOI: http://dx.doi.org/10.1007/s10570-015-0554-x.

[38] M. Sain, and S. Panthapulakkal. 2006. Bioprocess Preparation of Wheat Straw Fibers and Their Characterization. Industrial Crops and Products. 23(1): 1-8. DOI: http://dx.doi.org/10.1016/j.indcrop.2005.01.006.

[39] A. Alemdar, and M. Sain. 2008. Isolation and Characterization of Nanofibers from Agricultural Residues - Wheat Straw and Soy Hulls. Bioresource Technology. 99(6): 1664-1671. DOI: http://dx.doi.org/10.1016/j.biortech.2007.04.029.

[40] P. Aditiawati, R. Dungani, R.M. Fikri, and S. Hartati. 2019. Optimization of Cellulose Nanofiber Production from Oi Palm Empty Fruit Bunch Using Trichoderma Sp. with the Solid State Fermentation Method. BioResources. 14(2): 3688-3700.

DOI: https://ojs.cnr.ncsu.edu/index.php/BioRes/article/ view/BioRes_14_2_3688_Aditiawati_Optimization_Cellulose _Nanofiber_Production/6753. 